\title{
International
}

\section{Expanding Support for Political Science in the Arab Middle East and North Africa: MENA Workshops 2017-2019}

$\mathrm{T}$ he American Political Science Association is pleased to announce the next phase of our engagement with political scientists in the Arab Middle East and North Africa. With continued support from Carnegie Corporation of New York, we extend our commitment to enhancing the scholarly networks of earlycareer political science faculty from the MENA region.

The APSA MENA Workshops are an annual series of capacity-building workshops that bring together approximately 20 fellows, alongside four senior scholars, for training in research skills, professional development, peer review, and networking. The program is open to $\mathrm{PhD}$ candidates, post-docs, and early career faculty from across the Middle East and North Africa. Each program is dedicated to a substantive issue in political science with a unique schedule of lectures, discussions, research presentations, guest speakers, and professional development seminars. Throughout the workshops, fellows receive critical feedback on their own research and work to refine these manuscripts for publication. In the process, fellows form important professional networks of peer review, support, and collaboration.

Following their participation in the workshops, alumni are provided with complimentary membership to APSA and are eligible to apply for grants to facilitate further professional development and research collaboration. Alumni are regularly invited to present at the APSA annual meeting and other scholarly conferences.

The workshops have been hosted in cooperation with universities and research institutions across the MENA region since 2013.

\begin{tabular}{l} 
APSA MENA Workshops in Brief \\
\hline Series of week-long, residential, political science workshops \\
\hline Networking 20 scholars from the MENA region each year through 2019 \\
\hline More than $60 \%$ of our 84 alumni fellows are women \\
\hline Over $\$ 103,000$ in post-workshop alumni grants \\
\hline Institutional support to departments of political science through the region
\end{tabular}

Previous workshops have been held at the Alsalam Center for Development and Strategic Studies in Kuwait, the American University in Cairo, the American University of Beirut's Asfari Institute for Civil Society and Citizenship, the American Center of Oriental Research in Amman, the Center for Maghreb Studies in Tunis, Lebanese American University, and Qatar University's Social and Economic Survey Research Institute.

In the next phase of the program, we seek to expand institutional-level impact by providing resources and support to political science departments at public universities across the region. These departmental collaborations will build institutional support for student and faculty research training and professional development and strengthen the field of internationally inclusive and open political science scholarship.

Alongside APSA's other international programs, the APSA MENA Workshops are a concerted effort to engage with the international political science community and strengthen research networks linking US scholars with their colleagues overseas, as part of the association's 2017-2019 strategic plan. For program news, updates, and additional information see the project website: web.apsanet.org/mena/.

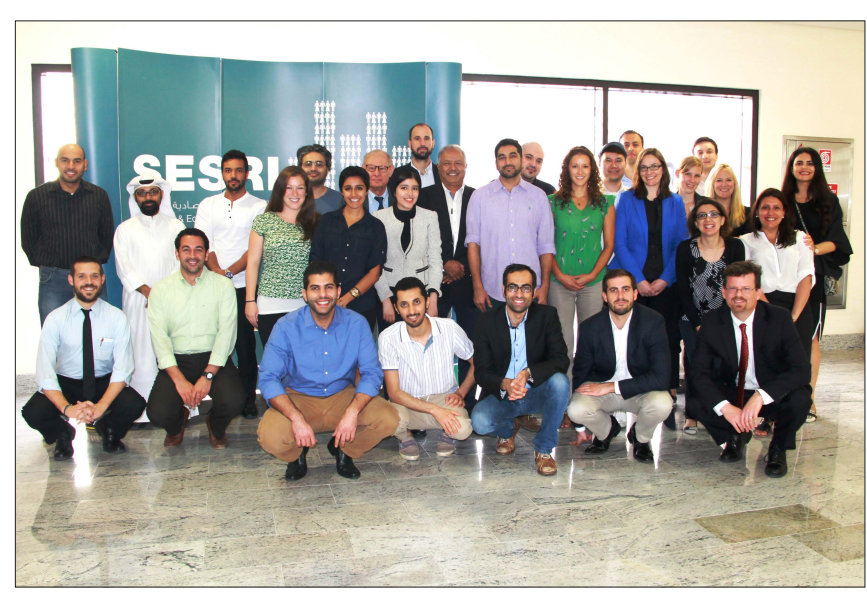

Fellows and coleaders of the May 2015 Workshop on "The Resource Curse in MENA" at Qatar University's Social and Economic Survey Research Institute (SESRI).

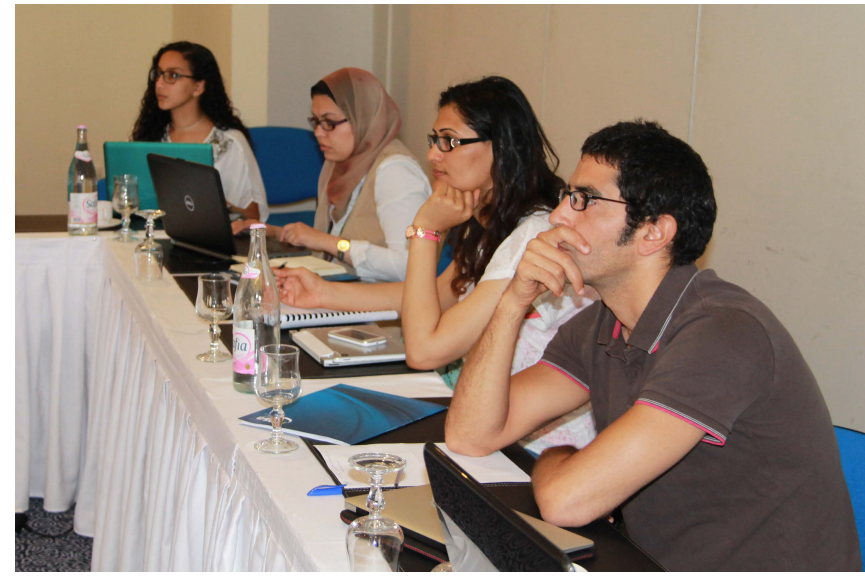

Fellows take notes during the June 2014 Workshop on “The Political Economy of Economic Development" in Tunis. 